\title{
PENERAPAN METODE SIMPLE ADDITIVE WEIGHTING UNTUK MENENTUKAN SISWA KURANG BERPRESTASI PADA JENJANG SEKOLAH DASAR BERBASIS WEB
}

\author{
Firdaus Dwi Cahya Kusuma, Sentot Achmadi, Suryo Adi Wibowo \\ Program Studi Teknik Informatika S1, Fakultas Teknologi Industri \\ Institut Teknologi Nasional Malang, Jalan Raya Karanglo km 2 Malang, Indonesia \\ 1618051@scholar.itn.ac.id
}

\begin{abstract}
ABSTRAK
Guru menyadari bahwa setiap siswa pastinya memiliki kemampuan yang berbeda-beda dalam menangkap materi yang diberikan pada saat kegiatan belajar mengajar dilaksanakan. apabila permasalahan tersebut tidak segera ditangani lama kelamaan dapat mempengaruhi tingkat kecerdasan masing-masing siswa. Oleh karena itu dibuatlah sistem untuk menentukan siswa kurang berprestasi agar guru dapat mengetahui dengan cepat kemampuan masing-masing siswa pada setiap mata pelajaran. Dalam pelakasanaannya sistem yang dibuat mempertimbangkan lima aspek kriteria penilaian dantaranya Nilai Ulangan Harian, Nilai Ujian Tengah Semester, Nilai Ujian Akhir Semester, serta Nilai Praktek dan Produk.

Sistem Pendukung Keputusan ini dibuat dengan menggunakan metode Simple Additive Weighting ( SAW ), yaitu mencari penjumlahan terbobot dari rating kinerja pada setiap alternatif pada semua atribut dengan proses normalisasi matriks keputusan $(\mathrm{X})$ ke suatu skala yang dapat diperbandingkan dengan semua rating alternatif yang ada.

Dengan adanya Sistem Pendukung Keputusan ini dapat menjadi solusi bagi guru SDN Wedoro dalam menentukan siswa yang kurang berprestasi agar memperoleh perhatian khusus untuk meningkatkan prestasinya. Dan hasil pengujian dari penelitian ini berupa daftar sepuluh siswa kurang berprestasi di masing-masing pelajaran dalam satu semester, dengan tingkat akurasi sistem dalam menentukan siswa kurang berprestasi sebesar $80 \%$.
\end{abstract}

Kata kunci : Sistem Pendukung Keputusan, Simple Additive Weighting, Siswa Kurang Berprestasi

\section{PENDAHULUAN}

\subsection{Latar Belakang}

Pendidikan suatu proses pembelajaran pengetahuan, keterampilan, dan kebiasaan sekumpulan manusia yang diwariskan dari satu genereasi ke generasi selanjutnya melalui pengajaran, pelatihan, dan penelitian. Selain itu Pendidikan bertujuan untuk mengembangkan potensi diri masing - masing siswa agar dapat memiliki kecerdasan, akhlak mulia, kepribadian, kekuatan spiritual, dan keterampilan yang bermanfaat bagi diri sendiri dan masyarakat. Proses pendidikan atau belajar dapat dilakukan dimana saja mulai dari lingkungan keluarga, masyarakat, atau sekolah. Proses belajar pada lingkungan sekolah berupa Pendidikan formal yang terstuktur dan memiliki jenjang untuk mempelajari ilmu secara sistematis, mulai dari Pendidikan anak usia dini (PAUD), Pendidikan dasar (SD), Pendidikan menengah (SMP), Pendidikan atas (SMA/SMK), dan Perguruan tinggi (Universitas/Institut). SDN Wedoro merupakan sekolah dasar negeri yang terletak di desa wedoro, kecamatan bluluk, kabupaten lamongan yang menggunakan kurikulum 2013. Proses belajar mengajar dan materi yang diberikan kepada siswa

produk pada setiap mata pelajaran dari masingmasing siswa, yang kemudian dilakukan proses perangkingan sehingga dapat diperoleh pada SDN Wedoro sama dengan SD pada umumnya seperti, Pendidikan Agama, Kewarganegaraan, Bahasa Indonesia, Matematika, Ilmu Pengetahuan Alam, Ilmu Pendidikan Sosial, Kesenian, Olahraga, Bahasa Jawa, Bahasa Inggris, Bahasa Arab dan Ekstrakulikuler. Sekolah ini juga termasuk sekolah terbaik karena memiliki berbagai prestasi, mulai dari prestasi dibidang akademik mapun prestasi dibidang non-akademik. Setiap hari guru dengan rajin memberikan materi pembelajaran kepada siswa agar dapat memiliki prestasi yang baik. Namun setiap siswa pastinya memiliki kemampuan yang berbedabeda dalam menangkap materi yang diberikan, sehingga dapat mempengaruhi tingkat kecerdasan mereka. Berdasarkan alasan tersebut sekolah dapat melakukan tindakan dengan cara memberikan les atau bimbingan belajar tambahan bagi siswa yang kurang berprestasi agar dapat meningkatkan kemampuannya di bidang akademik sehingga sama dengan siswa yang lain. Namun dalam proses pemilihan siswa yang kurang berprestasi guru kelas masih menggunakan cara manual dengan menghitung nilai rata-rata setiap kriteria yaitu nilai ulangan harian, ujian tengah semester, ujian akhir semester, nilai praktek, dan nilai 
hasil 10 siswa kurang berprestasi. Karena data nilai yang diolah cukup banyak guru dapat menghabiskan waktu yang cukup lama untuk menentukan siswa yang kurang berprestasi.

Oleh karena itu dibutuhkan suatu sistem pendukung keputusan untuk menentukan siswa yang kurang berprestasi pada SDN Wedoro, sehingga dapat mebantu guru dalam memilah antara siswa yang berprestasi dan kurang berprestasi. Sistem yang dibentuk diharapkan dapat memotivasi orang tua untuk mendidik anaknya ketika berada di lingkungan rumah agar nilai indeks prestasinya meningkat. Pelaksanaan pembuatan website ini menerapkan metode Simple Additive Weighting dalam menentukan siswa kurang berprestasi karena peniliaian dari metode ini lebih tepat yang berdasarkan dari nilai kriteria dan bobot yang sudah ditentukan oleh SDN Wedoro.

\subsection{Rumusan Masalah}

Rumusan masalah pada pembuatan sistem pendukung keputusan ini sebagai berikut :

1. Bagaimana cara menentukan 10 siswa kurang berprestasi pada masing-masing pelajaran di SDN Wedoro pada kelas 5 ?

2. Bagaimana cara membuat sistem pendukung keputusan di SDN Wedoro berbasis web ?

\subsection{Tujuan}

Adapun tujuan dari pembuatan sistem pendukung keputusan ini adalah sebagai berikut :

1. Menerapkan metode Simple Additive Weighting pada sistem pendukung keputusan berbasis untuk mentukan siswa kurang berprestasi pada masing-masing pelajaran dengan menggunakan data siswa dan 11 nilai mata pelajaran pada kelas 5 di SDN Wedoro.

2. Membuat sistem pendukung keputusan dengan menggunakan bahasa pemrograman PHP dan database MySQL.

\subsection{Batasan Masalah}

Adapun batasan masalah dalam pembuatan sistem pendukung keputusan ini sebagai berikut :

1. Sistem pendukung keputusan yang dibuat berbasis web.

2. Metode yang digunakan dalam penelitian ini yaitu Simple Additive Weighting (SAW).

3. Penelitian ini dilaksanakan di Sekolah Dasar Negeri Wedoro, Kecamatan Sukorame, Kabupaten Lamongan, Jawa Timur.

4. Data yang digunakan untuk pengembangan sistem didapat dari raport siswa SDN Wedoro kelas 5 semester 1 .

5. Terdapat 11 mata pelajaran yang diujikan yaitu Pendidikan Agama Islam, Pendidikan Kewarganegaraan, Bahasa Indonesia, Matematika, Ilmu Pengetahuan Alam, Ilmu Pengetahuan Sosial, Senibudaya, Pendidikan
Jasmani, Bahasa Jawa, Bahasa Inggris, Bahasa Arab.

6. Peneltian ini menggunakan 5 kriteria yang telah ditentukan oleh sekolah diantaranya Nilai Ulangan Harian, Nilai Ujian Tengah Semester, Nilai Ujian Akhir Semester, Nilai Praktek, dan Nilai Produk.

7. 5 Kriteria dalam penelitian ini menggunakan proses normalisasi cost, yang berarti nilai terkecil pada masing-masing kriteria dianggap paling menguntungkan.

8. Bahasa pemrogaman yang digunakan adalah PHP Native, CSS, Bootstrap, Javascript dan untuk database menggunakan $M y S Q L$.

\section{TINJAUAN PUSTAKA}

\subsection{Penelitian terkait}

Penelitian tentang sistem pendukung keputusan telah banyak ditulis oleh para peneliti diantaranya seperti Helilintar, R dan kawan-kawan pada tahun 2016, yang berjudul Penerapan Metode SAW dan Fuzzy Dalam Sistem Pendukung Keputusan Penerimaan Beasiswa. Sistem yang mereka buat berfungsi dengan baik untuk memberikan rekomendasi penerimaan beasiswa dengan tingkat akurasi sebesar 68\% terhadap 10 orang sampel. Dan untuk bahan pertimbangan atau kriterianya yaitu nilai IPK, penghasilan orangtua, prestasi non akademik, dan jumlah tanggungan orangtua per semester. ${ }^{[1]}$

Selanjutnya pada tahun yang sama Sitohang, $\mathrm{H}$, dan Siboro, M, melakukan sebuah penelitian yang berjudul Aplikasi Sistem Pendukung Keputusan Penentuan Siswa Bermasalah Menggunakan Metode Saw Pada Sekolah Smp Swasta Mulia Pratama Medan. Penelitian tersebut berhasil diterapkan dengan cara menentukan kriteria yang digunakan sebagai acuan pengambilan keputusan diantaranya kepatuhan, nilai raport, kehadiran, dan jiwa social. Lalu dilakukan proses rating kecocokan setiap alternatif pada setiap kriteria, memberikan bobot pada masing-masing kriteria, melakukan normalisasi matriks dan proses terakhir yaitu melakukan perangkingan dari setiap alternatif pada setiap kriteria untuk mencari nilai terbesar dari setiap alternative untuk menentukan siswa bermasalah. ${ }^{[2]}$

Ditahun 2018 Abubakar, S mengembangkan Sistem Pendukung Keputusan Pemilihan Objek Wisata Kota Labuhan Bajo Menggunakan metode yang sama yaitu Simple Additive Weighting. Dengan mempertimbangkan 5 kriteria sebagai acuan yaitu toilet, penginapan, telekomunikasi, tempat ibdah, dan transportasi. Dengan adanya sistem ini dapat membantu pengguna untuk menentukan dengan pasti objek wisata yang cocok bagi mereka sesuai kriteria yang telah dipilih. ${ }^{\left[{ }^{[1]}\right.}$ 


\subsection{SPK}

Sistem Pendukung Keputusan (SPK) adalah sistem berbasis komputer yang menyajikan dan memproses informasi yang memungkinkan pembuatan keputusan menjadi lebih produktif, dinamis dan inovatif.

Definisi awal SPK menunjukkan SPK sebagai sebuah sistem yang dimaksudkan untuk mendukung para pengambil keputusan manajerial dalam situasi keputusan semiterstruktur. SPK dimaksudkan untuk menjadi alat bantu bagi para pengambil keputusan untuk memperluas kapabilitas mereka, namun tidak untuk menggantikan penilaian mereka. SPK ditujukan untuk keputusan-keputusan yang memerlukan penilaian atau pada keputusan-keputusan yang sama sekali tidak dapat didukung oleh algoritma ${ }^{[4]}$

\subsection{Metode Simple Additive Weigting}

Konsep dasar metode SAW adalah mencari penjumlahan terbobot dari rating kinerja pada setiap alternatif pada semua atribut. Konsep dasar metode SAW adalah mencari penjumlahan terbobot dari rating kinerja pada setiap alternatif pada semua atribut ${ }^{[5]}$

Dalam metode Simple Additive Weighting terdapat proses normalisasi rating kinerja setiap alternatif, dengan 2 cara seperti pada persamaan 2.1 dan 2.2 .

$$
\begin{aligned}
& \mathrm{r}_{\mathrm{ij}} ; \frac{\mathrm{x}_{\mathrm{ij}}}{\operatorname{Maxx}_{\mathrm{ij}}}:(\text { Benefit }) \\
& \mathrm{n}_{\mathrm{ij}} ; \frac{\operatorname{Min}_{\mathrm{ij}}}{\mathrm{M}_{\mathrm{ij}}}:(\text { Cost })
\end{aligned}
$$

$n_{\mathrm{i} j}$ merupakan rating kinerja ternormalisasi dari

setiap alternatif $A_{i}$ pada atribut $C_{j} . \mathrm{i}=$ baris $1,2, \ldots \mathrm{m}$ dan $\mathrm{j}=\operatorname{kolom} 1,2, \ldots . \mathrm{n} . \quad$ Max $x_{i j}$ pada persamaan 2.1

merupakan persamaan Benefit yang mana akan digunakan apabila nilai terbesar pada setiap kriteria merupakan nilai terbaik . Sedangkan Min $x_{i j}$ pada

persamaan 2.2 merupakan persamaan Cost yang akan digunakan apabila nilai terkecil dari setiap kriteria merupakan nilai terbaik.

Selanjutnya dilakukan proses perankingan setiap alternatif yang ditunjukan pada persamaan 2.3.

$$
V_{i}=\sum_{j=1}^{n} w_{j} r_{i j}
$$

$V_{\hat{i}}$ merupakan ranking setiap alternatif $A_{i}$ yang

didapatkan dengan cara menjumlah nilai dari perkalian masing-masing kriteria terhadap bobot yang telah ditentukan . Nilai terbesar yang dihasilkan dari persamaan merupakan nilai alternatif terbaik.

\section{METODE PENELITIAN}

\subsection{Blok Diagram Sistem}

Diagram blok pada Sistem Pendukung Keputusan untuk Admin dapat dilihat pada gambar dibawah ini :

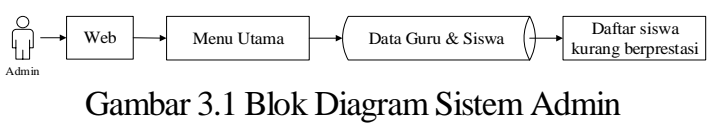

Pada gambar 3.1 menjelaskan bahwa pada web sistem pendukung keputusan untuk menentukan siswa kurang berprestasi, Admin dapat menambahkan data guru, siswa, dan kepala sekolah. Selain itu admin juga dapat melihat jumlah user guru, siswa, dan kepala sekolah yang terdaftar.

Diagram blok pada Sistem Pendukung Keputusan untuk Guru dapat dilihat pada gambar dibawah ini :

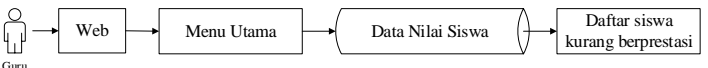

Gambar 3.2 Blok Diagram Sistem Guru

Gambar 3.2 menjelaskan bahwa pada web sistem pendukung keputusan untuk menentukan siswa kurang berprestasi, Guru dapat menginputkan nilai siswa dalam satu kelas untuk menentukan siswa yang kurang berprestasi, lalu hasilnya muncul pada daftar siswa yang kurang berprestasi.

Diagram blok pada Sistem Pendukung Keputusan untuk Siswa dapat dilihat pada gambar dibawah ini :

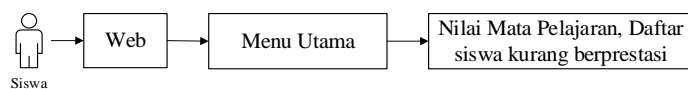

Gambar 3.3 Blok Diagram Sistem Siswa

Gambar 3.3 menjelaskan bahwa pada web sistem pendukung keputusan untuk menentukan siswa kurang berprestasi, Siswa dapat melihat nilai masing-masing pelajaran dan mengakses daftar siswa yang kurang berprestasi.

Diagram blok pada Sistem Pendukung Keputusan untuk Kepala Sekolah dapat dilihat pada gambar dibawah ini :

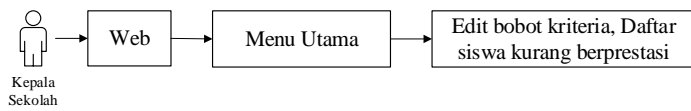

Gambar 3.4 Blok Diagram Sistem Kepala Sekolah

Gambar 3.4 menjelaskan bahwa pada web sistem pendukung keputusan untuk menentukan siswa kurang berprestasi, Kepala sekolah dapat mengakses daftar siswa yang kurang berprestasi dan menentukan nilai bobot masing - masing kriteria. 


\subsection{Flowchart sistem}

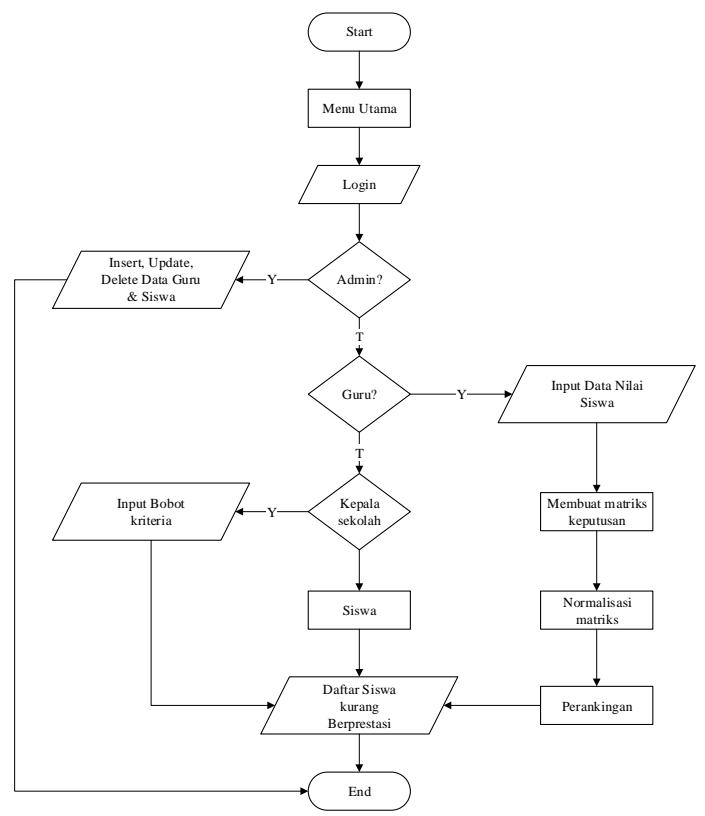

Gambar 3.5 Flowchart Sistem

Gambar 3.5 diatas merupakan kinerja sistem dimana pengguna diarahkan ke halaman utama website. Kemudian apabila admin melakukan login makan diarahkan kehalaman login untuk memasukan username dan password admin. Setelah melakukan login admin dapat melakukan pembuatan, pengeditan, penghapusan serta melihat user guru, kepala sekolah dan siswa yang terdaftar.

Pada saat kepala sekolah melakukan login, kepala sekolah dapat merubah nilai bobot, serta dapat melihat daftar 10 siswa yang termasuk dalam kategori siswa kurang berprestasi.

Apabila guru melakukan login guru diharuskan untuk menginputkan username dan password guru. Setelah melakukan login guru akan diarahkan ke laman guru untuk melakukan pengecekan siswa kurang berprestasi. Didalam laman ini terdapat proses perhitungan Simple Additive Weighting untuk menentukan siswa kurang berprestasi.

Kemudian apabila siswa ingin melakukan login siswa diharapkan untuk memasukan username dan password siswa. Setelah melakukan login siswa akan diarahkan ke laman siswa dimana didalamnya terdapat informasi nilai ulangan harian, ujian tengah semester, ujian akhir semester, praktek dan produk. Selain itu siswa juga dapat melihat daftar siswa kurang berprestasi di masing - masing mata pelajaran.

\subsection{Struktur Menu}

Gambar 3.6 menujukan beberapa sub menu yang disediakan oleh sistem. Pada menu home berisi tentang keterangan sistem dan bio sekolah. Pada menu data guru dan siswa berisi data guru dan siswa yang bisa diakses oleh admin. Untuk kriteria, bobot,hanya dapat diakses oleh kepala sekolah, dan nilai siswa hanya bisa diakses oleh guru. Untuk menu daftar siswa kurang berprestasi dapat diakses kepala sekolah, guru, dan siswa guna melihat hasil perhitungan. Dan untuk menu login digunakan sebagai input hak akses.

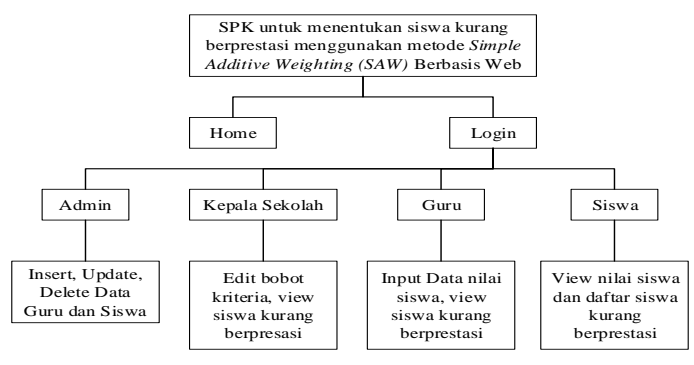

Gambar 3.6 Struktur Menu

\subsection{Data penelitian}

\subsubsection{Kriteria dan bobot}

Pada tabel kriteria terdapat 5 aspek penilaian dalam penetuan prestasi siswa yang terdiri dari ulangan harian yang diberi bobot $20 \%$, ujian tengah semester $15 \%$, ujian akhir semester $15 \%$, praktek 25 $\%$, serta produk $25 \%$. Seperti pada tabel 3.1.

Tabel 3.1 Kriteria dan Bobot

\begin{tabular}{|c|c|l|c|}
\hline No & ID & \multicolumn{1}{|c|}{ Nama Kriteria } & Bobot \\
\hline 1. & C1 & Ulangan Harian & $20 \%$ \\
\hline 2. & C2 & Ujian Tengah Semester & $15 \%$ \\
\hline 3. & C3 & Ujian Akhir Semester & $15 \%$ \\
\hline 4. & C4 & Praktek & $25 \%$ \\
\hline 5. & C5 & Produk & $25 \%$ \\
\hline
\end{tabular}

\subsubsection{Alternatif}

Merupakan daftar siswa kelas 5 yang akan diujikan tingkat prestasinya berdasarkan nilai akademik pada 5 kriteria penilaian yaitu nilai ulangan harian, ujian tengah semester, ujian akhir semester, praktek dan produk. Seperti pada tabel 3.2.

\begin{tabular}{|c|c|l|c|}
\hline NO & INDUK & \multicolumn{1}{|c|}{ NAMA } & $\begin{array}{c}\text { Jenis } \\
\text { Kelamin }\end{array}$ \\
\hline 1 & 1306 & Aisa Nurul Fadhilah & Laki - laki \\
\hline 2 & 1307 & $\begin{array}{l}\text { Alfian Ardianto } \\
\text { Prasetya }\end{array}$ & Perempuan \\
\hline 3 & 1308 & Anjar Dian Lestari & Perempuan \\
\hline 4 & 1309 & Damar Cahya Afreza & Perempuan \\
\hline 5 & 1310 & Echa Lelyana Putri & Laki - laki \\
\hline 6 & 1311 & Faizah Bintang Adira & Perempuan \\
\hline 7 & 1312 & $\begin{array}{l}\text { Felis Dea Nova } \\
\text { Aditia }\end{array}$ & Laki - laki \\
\hline 8 & 1313 & $\begin{array}{l}\text { Ghatan Meindra } \\
\text { Seftiawan }\end{array}$ & Laki - laki \\
\hline 9 & 1314 & Gilang Candra Mukti & Laki - laki \\
\hline 10 & 1315 & $\begin{array}{l}\text { Hellena Dea Adelia } \\
\text { Fauziah }\end{array}$ & Perempuan \\
\hline
\end{tabular}




\section{HASIL DAN PEMBAHASAN}

\subsection{Hasil Implementasi}

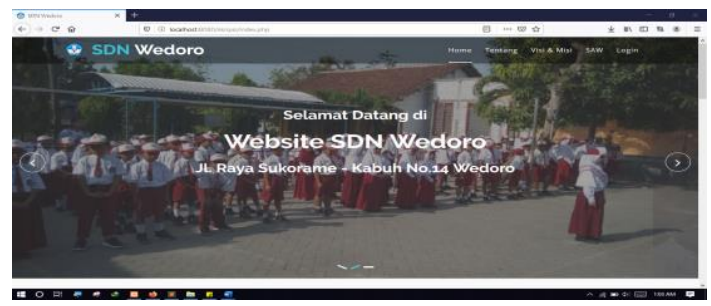

Gambar 4.1 Halaman Home

Home pada menu utama merupakan slide foto kegiatan yang dilakukan oleh SDN Wedoro. Dan merupakan antarmuka utama dari web penentuan siswa kurang berprestasi.

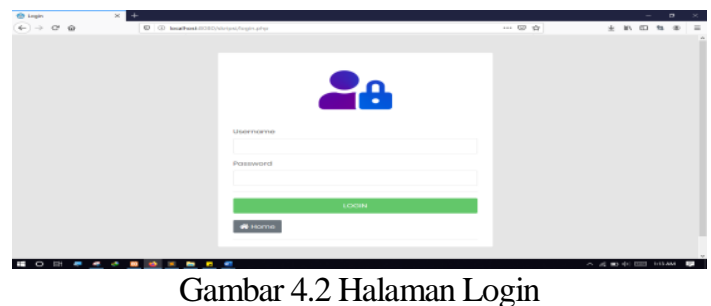

Menu login merupakan fitur yang digunakan untuk memulai sebuah sesi. Didalam website SDN Wedoro ini terdapat 3 hak akses yaitu admin, guru, dan siswa. Dari ketiga hak akses ini memiliki tugas yang berbeda, dimana admin berfungsi untuk menambah atau menghapus user guru atau siswa. Guru bertugas untuk menginputkan nilai serta dapat mencari atau menentukan siswa yang kurang berprestasi. Dan siswa hanya dapat melihat input nilai dari guru serta daftar 10 siswa kurang berprestasi pada masing-masing mata pelajaran.

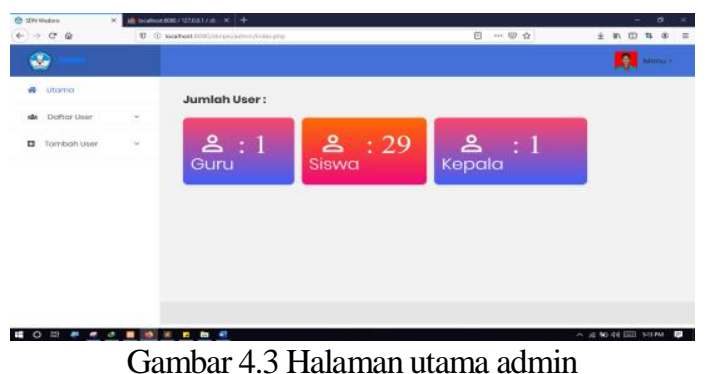

Pada menu tampilan utama admin terdapat 2 form yaitu yang berfungsi untuk menghitung jumlah user yang terdaftar dalam database. Sehingga admin dapat mengetahuin apabila terdapat siswa yang belum terdaftar.

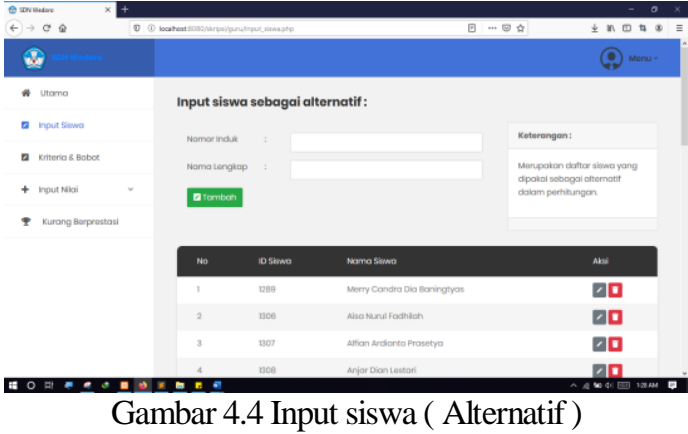

Pada menu input siswa merupakan halaman untuk memasukkan siswa dalam satu kelas yang akan dijadikan sebagai alternative pada perhitungan Simple Additive Weighting ( $S A W$ ).

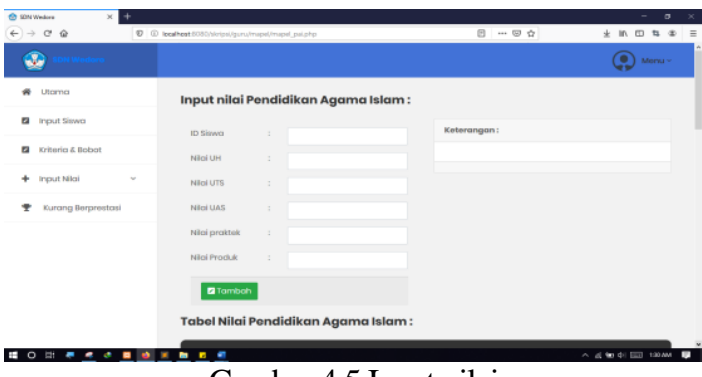

Gambar 4.5 Input nilai

Pada halaman input nilai berfungsi untuk memasukan niai yang dimiliki oleh setiap alternative ( siswa ) terhadap setiap kriteria dalam masingmasing mata pelajaran untuk dihitung secara matematis menggunakan metode SAW.

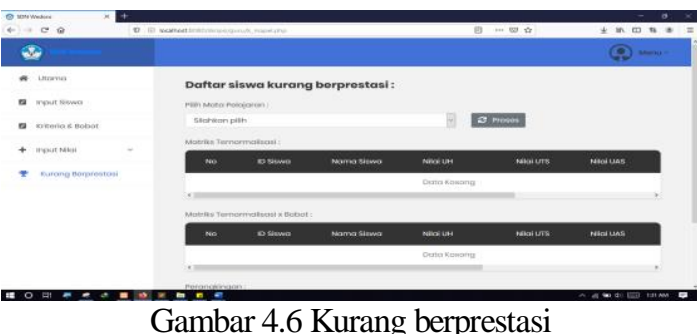

Menu kurang berprestasi merupakan halaman yang berfungsi untuk menampilkan perhitungan dari metode Simple Additive Weighting ( $S A W$ ) dari input alternative serta input nilai sehingga diperoleh 10 daftar siswa kurang berprestasi. Didalamnya juga memaparkan langkah langkah perhitungan yang dirangkum dalam sebuah tabel.

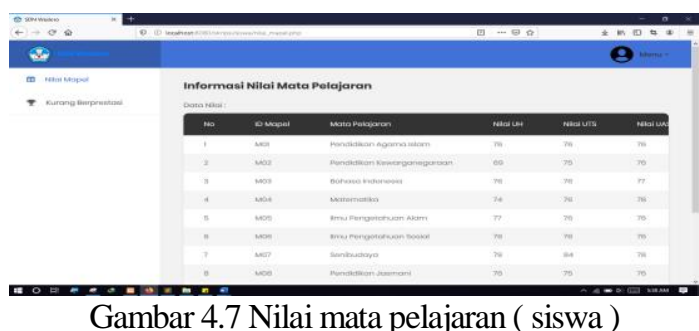


Dalam halaman ini siswa dapat melihat nilai akademik mereka pada setiap mata pelajaran yang telah di input oleh guru berdasarkan nomor induk masing-masing siswa.

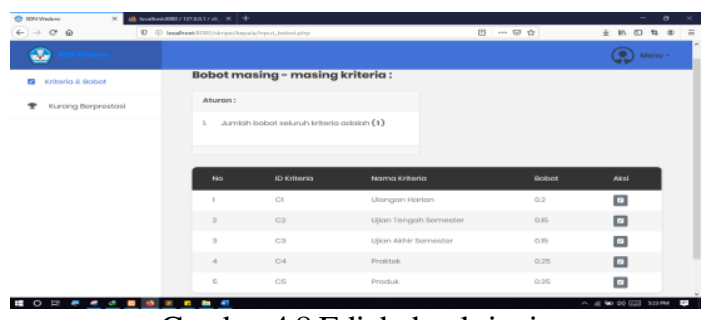

Gambar 4.8 Edit bobot kriteria

Kriteria dan bobot merupakan menu yang berfungsi untuk merubah nilai bobot yang tersimpan. Dalam kriteria yang diberikan oleh SDN Wedoro ada 5 yaitu nilai ulangan harian yang berbobot $20 \%$, ujian tengah semester dan akhir semester yang masingmasing memiliki bobot $15 \%$, nilai praktek dan produk memiliki bobot masing-masing $25 \%$.

\subsection{Pengujian}

4.2.1 Pengujian metode Saw

1. Melakukan Rating Kecocokan setiap Alternatif pada setiap Kriteria.

Pada tahap ini guru memasukan nilai tiap alternatif ( siswa ) pada masing-masing kriteria yang telah ditentukan berdasarkan nilai akademik siswa.

Tabel 4.1 Input nilai

\begin{tabular}{|c|l|c|c|c|c|c|}
\hline \multirow{2}{*}{ ID } & \multicolumn{1}{|c|}{ Nama } & \multicolumn{5}{|c|}{ PAI } \\
\cline { 3 - 7 } & & C1 & C2 & C3 & C4 & C5 \\
\hline A1 & Aisa Nurul Fadhilah & 80 & 80 & 80 & 80 & 80 \\
\hline A2 & $\begin{array}{l}\text { Alfian Ardianto } \\
\text { Prasetya }\end{array}$ & 75 & 75 & 75 & 75 & 75 \\
\hline A3 & Anjar Dian Lestari & 85 & 87 & 85 & 88 & 88 \\
\hline A4 & Damar Cahya Afreza & 78 & 79 & 78 & 78 & 78 \\
\hline A5 & Echa Lelyana Putri & 89 & 89 & 89 & 85 & 85 \\
\hline A6 & Faizah Bintang Adira & 90 & 92 & 90 & 88 & 88 \\
\hline A7 & $\begin{array}{l}\text { Felis Dea Nova } \\
\text { Aditia }\end{array}$ & 79 & 79 & 79 & 78 & 78 \\
\hline A8 & $\begin{array}{l}\text { Ghatan Meindra } \\
\text { Seftiawan }\end{array}$ & 77 & 78 & 77 & 76 & 77 \\
\hline A9 & Gilang Candra Mukti & 79 & 79 & 79 & 78 & 78 \\
\hline A10 & $\begin{array}{l}\text { Hellena Dea Adelia } \\
\text { Fauziah }\end{array}$ & 87 & 87 & 87 & 84 & 84 \\
\hline
\end{tabular}

\section{Membuat matriks keputusan ( X )}

Matriks keputusan diperoleh dari rating kecocokan kinerja setiap siswa ( alternatif ) terhadap kriteria yang telah ditentukan.

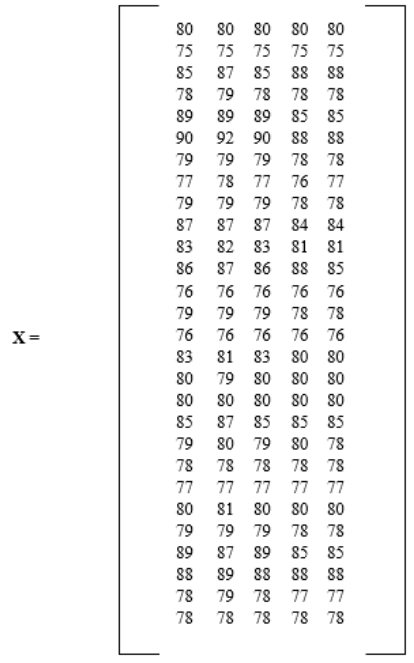

\section{Proses normalisasi}

Pada proses ini ( rij ) diperoleh dari rating kinerja tiap alternatif $\mathrm{Ai}$ terhadap kriteria $\mathrm{C}$, berdasarkan persamaan yang telah disesuaikan.

Tabel 4.2 Normalisasi

\begin{tabular}{|c|c|c|c|c|c|}
\hline \multirow{2}{*}{ ID } & \multicolumn{5}{|c|}{ Normalisasi } \\
\cline { 2 - 6 } & C1 & C2 & C3 & C4 & C5 \\
\hline A1 & 0.9375 & 0.9375 & 0.9375 & 0.9375 & 0.9375 \\
\hline A2 & 1 & 1 & 1 & 1 & 1 \\
\hline A3 & 0.882353 & 0.862069 & 0.882353 & 0.852273 & 0.852273 \\
\hline A4 & 0.961538 & 0.949367 & 0.961538 & 0.961538 & 0.961538 \\
\hline A5 & 0.842697 & 0.842697 & 0.842697 & 0.882353 & 0.882353 \\
\hline A6 & 0.833333 & 0.815217 & 0.833333 & 0.852273 & 0.852273 \\
\hline A7 & 0.949367 & 0.949367 & 0.949367 & 0.961538 & 0.961538 \\
\hline A8 & 0.974026 & 0.961538 & 0.974026 & 0.986842 & 0.974026 \\
\hline A9 & 0.949367 & 0.949367 & 0.949367 & 0.961538 & 0.961538 \\
\hline A10 & 0.862069 & 0.862069 & 0.862069 & 0.892857 & 0.892857 \\
\hline
\end{tabular}

\section{Perankingan}

Perankingan dilakukan setelah matriks normalisasi dihasilkan. Pada proses perankingan ini dilakukan perkalian antara matriks normalisasi dengan bobot masing-masing kriteria sehingga didapatkan nilai keputusan dari tinggi ke rendah.

Tabel 4.3 Perankingan

\begin{tabular}{|c|c|c|c|c|c|c|}
\hline \multirow{2}{*}{ ID } & \multicolumn{5}{|c|}{ Normalisasi x Bobot } & \multirow{2}{*}{ Total } \\
\hline & Cl & $\mathrm{C} 2$ & C3 & C4 & C5 & \\
\hline A1 & 0.1875 & 0.140625 & 0.140625 & 0.234375 & 0.234375 & 0.9375 \\
\hline A2 & 0.2 & 0.15 & 0.15 & 0.25 & 0.25 & 1 \\
\hline A3 & 0.176471 & 0.12931 & 0.132353 & 0.213068 & 0.213068 & 0.86427 \\
\hline A4 & 0.192308 & 0.142405 & 0.144231 & 0.240385 & 0.240385 & 0.959713 \\
\hline A5 & 0.168539 & 0.126404 & 0.126404 & 0.220588 & 0.220588 & 0.862525 \\
\hline A6 & 0.166667 & 0.122283 & 0.125 & 0.213068 & 0.213068 & 0.840086 \\
\hline A7 & 0.189873 & 0.142405 & 0.142405 & 0.240385 & 0.240385 & 0.955453 \\
\hline A8 & 0.194805 & 0.144231 & 0.146104 & 0.246711 & 0.243506 & 0.975357 \\
\hline A9 & 0.189873 & 0.142405 & 0.142405 & 0.240385 & 0.240385 & 0.955453 \\
\hline A10 & 0.172414 & 0.12931 & 0.12931 & 0.223214 & 0.223214 & 0.877463 \\
\hline
\end{tabular}

\section{Keputusan}

Dari nilai total pada proses perankingan selanjutnya dilakukan pengambilan keputusan untuk memilih sepuluh siswa yang memiliki nilai total tertinggi. 
Tabel 4.4 Keputusan

\begin{tabular}{|c|c|c|c|c|c|c|c|c|}
\hline \multirow[b]{2}{*}{ №. } & \multirow[b]{2}{*}{ Nama } & \multicolumn{5}{|c|}{ Normalisasi x Bobot } & \multirow{2}{*}{$\begin{array}{c}\text { Total } \\
\text { (Analisis) }\end{array}$} & \multirow{2}{*}{$\begin{array}{c}\text { Total } \\
\text { (Sistem) }\end{array}$} \\
\hline & & $\mathrm{Cl}$ & $\mathrm{C}_{2}$ & C3 & C4 & C5 & & \\
\hline 1. & \begin{tabular}{|l|} 
Alfian Ardianto \\
Praserva
\end{tabular} & 0.2 & 0.15 & 0.15 & 0.25 & 0.25 & 1 & 1 \\
\hline 2. & $\begin{array}{l}\text { M. Devan Nelshen } \\
\text { Alvvnno Bastyan }\end{array}$ & 0.197368 & 0.148026 & 0.148026 & 0.246711 & 0.246711 & 0.986842 & 0.986842 \\
\hline 3. & $\begin{array}{l}\text { Merry Candra Dia } \\
\text { Baningtvas } \\
\end{array}$ & 0.197368 & 0.148026 & 0.148026 & 0.246711 & 0.246711 & 0.986842 & 0.986842 \\
\hline 4. & \begin{tabular}{|l|} 
Ghatan Meindra \\
Seftiawan
\end{tabular} & 0.194805 & 0.144231 & 0.146104 & 0.246711 & 0.243506 & 0.975357 & 0.975357 \\
\hline 5. & \begin{tabular}{|l|} 
Nayla Dwi Olivia \\
\end{tabular} & 0.194805 & 0.146104 & 0.146104 & 0.243506 & 0.243506 & 0.974026 & 0.974026 \\
\hline 6. & $\begin{array}{l}\text { Umi Nilkatum } \\
\text { Nanda }\end{array}$ & 0.192308 & 0.142405 & 0.144231 & 0.243506 & 0.243506 & 0.965957 & 0.965957 \\
\hline 7. & \begin{tabular}{|l|} 
Natasya Maharani \\
\end{tabular} & 0.192308 & $\begin{array}{ll}0.144231 \\
\end{array}$ & \begin{tabular}{|l|l|l|l|l|l|l} 
& \\
\end{tabular} & \begin{tabular}{ll|l}
0.240385 \\
\end{tabular} & 0.240385 & 0.961538 & 0.961538 \\
\hline 8. & \begin{tabular}{|l} 
Zanuar Rendra \\
Refangag Kiswivan \\
Putra \\
\end{tabular} & 0.192308 & 0.144231 & 0.144231 & 0.240385 & 0.240385 & 0.961538 & 0.961538 \\
\hline 9. & $\begin{array}{l}\text { Damar Cahya } \\
\text { Afreza }\end{array}$ & 0.192308 & 0.142405 & 0.144231 & 0.240385 & 0.240385 & 0.959713 & 0.959713 \\
\hline 10. & $\begin{array}{l}\text { Felis Dea Nova } \\
\text { Aditia }\end{array}$ & 0.189873 & 0.142405 & 0.142405 & 0.240385 & 0.240385 & 0.955453 & 0.955453 \\
\hline
\end{tabular}

\subsubsection{Persentase error sistem}

Pada tahap ini dilakukan pengecekan error penentuan siswa kurang berprestasi dengan cara membandingkan hasil perhitungan manual dan sistem dengan persamaan :

$$
\text { error }=\frac{\text { totalststem }- \text { totalanausis }]}{\text { totalanalisis }} \times 10036
$$

Didapatkan hasil :

Tabel 4.5 Persentase error

\begin{tabular}{|c|l|c|c|}
\hline No. & \multicolumn{1}{|c|}{ Mata Pelajaran } & $\begin{array}{c}\text { Daftar Siswa } \\
\text { yang sesuai }\end{array}$ & $\begin{array}{c}\text { Persentase } \\
\text { (Error) }\end{array}$ \\
\hline 1. & Pendidikan Agama Islam & 7 & $30 \%$ \\
\hline 2. & Pendidikan Kewarganegaraan & 9 & $10 \%$ \\
\hline 3. & Bahasa Indonesia & 9 & $10 \%$ \\
\hline 4. & Matematika & 6 & $40 \%$ \\
\hline 5. & Ilmu Pengetahuan Alam & 9 & $10 \%$ \\
\hline 6. & Ilmu Pengetahuan Sosial & 8 & $20 \%$ \\
\hline 7. & Senibudaya & 9 & $10 \%$ \\
\hline 8. & Pendidikan Jasmani & 8 & $20 \%$ \\
\hline 9. & Bahasa Jawa & 7 & $30 \%$ \\
\hline 10. & Bahasa Inggris & 7 & $30 \%$ \\
\hline 11. & Bahasa Arab & 9 & $10 \%$ \\
\hline \multicolumn{2}{|c|}{ Rata - Rata } & $20 \%$ \\
\hline
\end{tabular}

Maka diperoleh hasil dengan tingkat error sistem seperti pada tabel 4.5. Menunjukkan kesesuaian sistem dalam menentukan 10 siswa kurang berprestasi di masing-masing pelajaran. salah satu contohnya yaitu hasil dari sistem pada mata pelajaran Pendidikan Agama Islam menampilkan 10 siswa kurang berprestasi namun, dari hasil yang tampilkan hanya terdapat 7 siswa yang sesuai. Dengan melakukan perhitungan menggunakan persamaan 4.1 maka diperoleh nilai persentase error pada mata pelajaran Pendidikan Agama Islam sebesar $30 \%$. Setelah mencari persentase error pada setiap mata pelajaran diperoleh rata-rata error sebesar $20 \%$, yang artinya tingkat akurasi sistem dalam menentukan 10 siswa kurang berprestasi pada masing-masing pelajaran sebesar $80 \%$.

\subsubsection{Pengujian Fungsionalitas website}

Pada pengujian fungsionalitas sistem, dilakukan percobaan untuk menjalankan semua fungsi yang ada disistem, apakah bekerja dengan normal atau tidak. Pengujian dilaukan pada 2 browser pada google chrome dan firefox.
Tabel 4.6 Fungsionalitas sistem

\begin{tabular}{|c|c|c|c|}
\hline $\begin{array}{c}\text { Hak } \\
\text { Akses }\end{array}$ & Fungsi & $\begin{array}{l}\text { Google } \\
\text { Chrome }\end{array}$ & Firefox \\
\hline \multirow{6}{*}{ Admin } & Login, Logout dan Sesi admin & $\checkmark$ & $\checkmark$ \\
\hline & Menu utama admin & $\checkmark$ & $\checkmark$ \\
\hline & $\begin{array}{l}\text { Daftar } \text { user guru, kepala sekolah } \\
\text { dan siswa }\end{array}$ & $\checkmark$ & $\checkmark$ \\
\hline & $\begin{array}{l}\text { Tambah guru, kepala sekolah } \\
\text { dan siswa }\end{array}$ & $\checkmark$ & $\checkmark$ \\
\hline & $\begin{array}{l}\text { Edit guru, kepala sekolah, dan } \\
\text { siswa }\end{array}$ & $\checkmark$ & $\checkmark$ \\
\hline & $\begin{array}{l}\text { Delete guru, kepala sekolah, dan } \\
\text { siswa }\end{array}$ & $\checkmark$ & $\checkmark$ \\
\hline \multirow{5}{*}{ Guru } & Login, Logout dan Sesi guru & $\checkmark$ & $\checkmark$ \\
\hline & Menu utama guru & $\checkmark$ & $\checkmark$ \\
\hline & $\begin{array}{l}\text { Input, Read, Update, Delete } \\
\text { siswa ( alternatif) }\end{array}$ & $\checkmark$ & $\checkmark$ \\
\hline & $\begin{array}{l}\text { Input, Read, Update, Delete nilai } \\
\text { mata pelajaran }\end{array}$ & $\checkmark$ & $\checkmark$ \\
\hline & $\begin{array}{l}\text { Menu daftar siswa kurang } \\
\text { berprestasi }\end{array}$ & $\checkmark$ & $\checkmark$ \\
\hline \multirow{3}{*}{$\begin{array}{l}\text { Kepala } \\
\text { sekolah }\end{array}$} & $\begin{array}{l}\text { Login, Logout dan Sesi kepala } \\
\text { sekolah }\end{array}$ & $\checkmark$ & $\checkmark$ \\
\hline & Edit nilai bobot kriteria & $\checkmark$ & $\checkmark$ \\
\hline & Daftar siswa kurang berprestasi & $\checkmark$ & $\checkmark$ \\
\hline \multirow{3}{*}{ Siswa } & $\begin{array}{l}\text { Login, Logout dan Sesi kepala } \\
\text { sekolah }\end{array}$ & $\checkmark$ & $\checkmark$ \\
\hline & Tampil nilai siswa & $\checkmark$ & $\checkmark$ \\
\hline & Daftar siswa kurang berprestasi & $\checkmark$ & $\checkmark$ \\
\hline
\end{tabular}

\subsubsection{Pengujian user}

Pengujian user merupakan nilai atau respon yang diberikan oleh user terhadap aplikasi. Pada penelitian ini, kuisioner diberikan kepada pihak guru, kepala sekolah, dan siswa atau wali pada SDN Wedoro. Seperti pada tabel 4.7 berikut.

Tabel 4.7 Pengujian user

\begin{tabular}{|c|c|c|c|c|}
\hline \multirow{2}{*}{ No } & \multirow{2}{*}{ Pertanyaan } & \multicolumn{3}{|c|}{ Respond user } \\
\hline & & Baik & Cukup & Kurang \\
\hline 1 & $\begin{array}{l}\text { Apakah ukuran dan warna font } \\
\text { sudah terlihat dengan jelas? }\end{array}$ & 2 & & \\
\hline 2 & $\begin{array}{l}\text { Apakah tampilan website sudah } \\
\text { sesuai kebutuhan? }\end{array}$ & 2 & & \\
\hline 3 & $\begin{array}{l}\text { Apakah warna tombol dan } \\
\text { background pada aplikasi sudah } \\
\text { sesuai dan terlihat jelas? }\end{array}$ & 2 & & \\
\hline 4 & $\begin{array}{l}\text { Apakah tampilan menu-menu } \\
\text { program mudah dipahami? }\end{array}$ & 2 & & \\
\hline 5 & $\begin{array}{l}\text { Apakah form-form yang ada } \\
\text { pada program sudah sesuai? }\end{array}$ & 2 & & \\
\hline 6 & $\begin{array}{l}\text { Apakah program membantu } \\
\text { mempermudah proses penentuan } \\
\text { siswa kurang berprestasi ? }\end{array}$ & 2 & & \\
\hline & TOTAL & 12 & & \\
\hline
\end{tabular}

Dari perolehan pengujian user telah didapatkan nilai 12 pada nilai total yang mana nilai tersebut di dapatkan dari 2 responden yaitu Kepala Sekolah dan Guru SDN Wedoro. Setiap pertanyaan pada kuisioner bernilai 1 .

\section{KESIMPULAN DAN SARAN}

\subsection{Kesimpulan}

Adapun kesimpulan yang dapat penulis uraikan setelah melakukan perancangan dan pembuatan sistem pendukung keputusan menggunakan metode SAW adalah sebagai berikut : 
1. Sistem pendukung keputusan ini dapat di implementasikan di SDN Wedoro serta menentukan sepuluh siswa kurang berprestasi dari hasil nilai total perhitungan masing-masing kriteria.

2. Berdasarkan hasil perhitungan sistem siswa kurang berprestasi di SDN Wedoro pada mata pelajaran Pendidikan Agama Islam semester 1 diperoleh nilai tertinggi yaitu 1 .

3. Persentase tingkat error atau kesalahan sistem dalam melakukan keputusan sebesar $20 \%$ yang artinya tingkat akurasi sistem dalam menentukan siswa kurang berprestasi sebesar $80 \%$.

4. Hasil dari pengujian user bahwa tampilan, fungsi atau kegunaan sesuai yang diharapkan dan berjalan dengan baik, yang mana untuk penilaian pengujian user diperoleh nilai baik sebesar 12 dari 6 pertanyaan yang diajukan kepada 2 responden yaitu Kepala sekolah dan guru.

5. Pada pengujian fungsionalitas sistem, semua fungsi pada masing-masing hak akses dari admin, kepala sekolah, guru dan siswa dapat berjalan dengan lancar pada web browser google chrome dan firefox.

\subsection{Saran}

Berdasarkan kesimpulan yang telah diuraikan diatas, maka diberikan saran sebagai berikut :

1. Guru dapat memanfaatkan sistem untuk membantu dalam pengambilan keputusan penentuan siswa kurang berprestasi pada masingmasing pelajaran dengan kriteria dan bobot yang telah ditentukan.

2. Dengan adanya sistem ini Kepala sekolah dapat mengetahui siswa yang kurang berprestasi pada masing-masing pelajaran, serta dapat mengubah nilai bobot masing-masing kriteria sesuai dengan ketentuan yang sudah di sepakati oleh sekolah.
3. Siswa dapat termotivasi untuk meningkatkan prestasinya agar tidak masuk dalam daftar sepuluh siswa kurang berprestasi.

4. Perhitungan menggunakan metode Simple Additive Weighting (SAW) lebih cocok digunakan untuk menghitung nilai atau variabel yang belum pasti.

\section{DAFTAR PUSTAKA}

[1] Helilintar, R. 2016. Penerapan Metode SAW dan Fuzzy Dalam Sistem Pendukung Keputusan Penerimaan Beasiswa. STMIK AMIKOM Yogyakarta.

[2] Sitohang, H, dan Siboro, M. 2016. Aplikasi Sistem Pendukung Keputusan Penentuan Siswa Bermasalah Menggunakan Metode Saw Pada Sekolah Smp Swasta Mulia Pratama Medan. STMIK Pelita Nusantara Medan.

[3] Abubakar, S, 2017, PENGEMBANGAN SISTEM PENDUKUNG KEPUTUSAN PEMILIHAN OBJEK WISATA KOTA LABUAN BAJO MENGGUNAKAN METODE SIMPLE ADDITIVE WEIGHTING (SAW).

[4] Adi Wibowo, S., \& Agus Pranoto, Y., 2015. APLIKASI SISTEM PENDUKUNG KEPUTUSAN SEBAGAI FILTER PENERIMA BEASISWA MENGGUNAKAN MODEL ANALYTICAL HIERARCHY PROCESS. INDUSTRI INOVATIF, 5(1), 4252.

[5] Kaputama, Metode Simple Additive Weighting (SAW), 2014. Melalui : http://www.kaputama.ac.id/sites/default/files/M etode-SAW

[6] Frieyadie, F. (2016). Penerapan Metode Simple Additive Weight (SAW) Dalam Sistem Pendukung Keputusan Promosi Kenaikan Jabatan. Jurnal Pilar Nusa Mandiri, 12(1), 3745. 